\title{
Notas sobre a influência de Carlos Nelson Coutinho ao Serviço Social brasileiro
}

\author{
Mabile Caetano Cazela \\ Universidade Estadual do Oeste do Paraná (UNIOESTE)
}

\section{Notas sobre a influência de Carlos Nelson Coutinho ao Serviço Social brasileiro}

Resumo: O artigo apresenta alguns resultados da pesquisa para dissertação de mestrado em Serviço Social, princípios éticos fundamentais do Serviço Social brasileiro: um estudo sobre a influência de Carlos Nelson Coutinho. Parte de uma pesquisa bibliográfica e de campo, identificando e (re)conhecendo a influência de Coutinho para o Serviço Social, bem como a contribuição intelectual de Assistentes Sociais, membros da Comissão de Reformulação do Código de Ética.

Palavras-chave: Serviço Social. Princípios éticos fundamentais. Carlos Nelson Coutinho.

\section{Notes on the influence of Carlos Nelson Coutinho on Social Work in Brazil}

Abstract: The paper reports some results of a research study conducted for the master's thesis in Social Work entitled Fundamental ethical principles of Social Work in Brazil: a study on the influence of Carlos Nelson Coutinho. It is based on bibliographic and field research, and it identifies and recognizes the influence of Coutinho on Social Work, as well as the intellectual contribution of Social Workers that are members of the Code of Ethics Revision Committee.

Keywords: Social Work. Fundamental ethical principles. Carlos Nelson Coutinho. 


\section{Introdução}

O presente artigo é fruto da pesquisa para a dissertação de mestrado do Programa de Pós-Graduação Stricto Sensu em Serviço Social da Universidade Estadual do Oeste do Paraná (UNIOESTE), campus de Toledo/PR, que teve como objeto de estudo o Serviço Social enquanto profissão inserida na divisão social e técnica do trabalho, envolvendo um debate sobre os fundamentos teórico-metodológicos que dão origem aos princípios éticos fundamentais presentes no Código de Ética vigente e que atravessam o projeto profissional construído historicamente, o denominado Projeto Ético-Político Profissional do Serviço Social. Nesta pesquisa, pensada e construída em conjunto com a orientadora, assistente social e professora doutora Esther Luíza de Souza Lemos, a problematização partiu do seguinte questionamento: qual a influência da tradição marxista através da produção intelectual de Carlos Nelson Coutinho na construção dos princípios éticos definidos no Código de Ética Profissional do(a) Assistente Social de 1993? No sentido de traçar e orientar os caminhos para a objetivação e sistematização do conhecimento em torno deste objeto, foram objetivos da pesquisa: contextualizar historicamente as condições objetivas para a emergência da concepção de projeto ético-político no Serviço Social brasileiro e do processo de reformulação do Código de Ética Profissional do(a) Assistente Social de 1993; recuperar a obra de Coutinho e sua relação com o Serviço Social brasileiro; apreender os fundamentos teórico-metodológicos dos princípios éticos definidos no Código de Ética Profissional do(a) Assistente Social de 1993 e a contribuição e influência da produção intelectual de Carlos Nelson Coutinho; identificar os elementos (conceitos ou categorias) que evidenciam a influência do pensamento de Carlos Nelson Coutinho na elaboração do Código de Ética.

Para os procedimentos metodológicos, partiu-se da pesquisa exploratória, abrangendo os delineamentos de pesquisa bibliográfica e de campo: a primeira, compreendida enquanto estudo e conhecimento de categorias e conceitos referentes ao objeto, que se sustenta a partir de pesquisas realizadas e na utilização de seus conteúdos, os quais podem ser fonte de aproximação, assim como engendrar novos problemas de pesquisa; a segunda, contemplando desde levantamentos mais descritivos até estudos mais analíticos, com a finalidade de maior aproximação às múltiplas determinações do objeto (GIL, 1996). Nesta etapa, foi realizada a técnica de entrevista, na qual a coleta dos dados foi feita por meio da utilização de: a) roteiro de entrevista - comum para todos os sujeitos, com o objetivo de extrair dos entrevistados o porquê de suas respostas, com intuito de ampliar a compreensão e análise sobre o conteúdo proposto aos sujeitos, abrindo à análise um viés qualitativo; b) gravador, para coletar na íntegra as falas dos sujeitos para posterior transcrição, análise e interpretação das mesmas. Os sujeitos da pesquisa foram selecionados de maneira intencional, dada a delimitação do objeto, portanto foram entrevistados Assistentes Sociais membros da Comissão Técnica Nacional de Reformulação do Código de Ética. Tais sujeitos aceitaram e foram identificados na pesquisa, isso porque: 1) tais profissionais já foram identificados desde a primeira edição de Bonetti (2012), isto é, desde 1996; 2) são pesquisadores renomados e autores de uma parte significativa da bibliografia do Serviço Social brasileiro; 3) considerando que ainda não há produção de conhecimento devidamente publicada sobre a problemática específica, tais sujeitos são fonte de saber teórico e histórico do processo investigado.

Assim, com atenção comprometida à eticidade da pesquisa, são sujeitos desta pesquisa: Beatriz A. Paiva; José Paulo Netto; Maria Lúcia Barroco; Marlise Vinagre; Mione A. Sales. Destes sujeitos convidados para a pesquisa, apenas Mione A. Sales não conseguiu/pôde atender ao convite ${ }^{1}$. Além disso, há que se ressaltar duas questões: a primeira é que, dentro da abertura da realização da pesquisa de campo no Rio de Janeiro, foi possível dialogar com Andréa de Paula Teixeira, que, embora não seja membro da referida comissão e, a princípio, não estivesse convidada diretamente, a partir de um encontro de acaso e uma breve conver$\mathrm{sa}^{2}$, na Escola de Serviço Social da UFRJ, com esta assistente social, docente, pesquisadora e que foi companheira de vários anos de Coutinho, ela se dispôs a dialogar sobre o tema; a segunda, é que a contribuição de Maria Lucia Barroco foi dada a partir de suas respostas com base no roteiro de entrevista, enviado por e-mail, devido condições objetivas postas ${ }^{3}$. Interessa apresentar parte dos resultados desta pesquisa, aquela que apresenta mais especificamente a influência indireta e direta de Carlos Nelson Coutinho, tendo em vista sua contribuição tanto na concepção ética e política, que rebatem e influenciam o Serviço Social brasileiro.

\section{Por que Coutinho?}

A relação de Carlos Nelson Coutinho com o Serviço Social brasileiro pode-se configurar, para muitos, uma relação muito distante ou incompatível, já que o primeiro é um filósofo e, portanto, não teria relação direta com a segunda, uma profissão de natureza interventiva, como se sabe. De outro lado, há quem compreenda esta relação como uma questão óbvia, uma vez que Coutinho foi uma pessoa que fez filosofia política, foi um 
pensador, professor, militante e intelectual no âmbito da tradição marxista; e que o Serviço renova suas diretrizes fundamentais, recusando ao conservadorismo teórico-metodológico e profissional, a partir do contato e aproximação com a tradição marxista. Mas, estas, são duas concepções diametralmente opostas. Refutando à primeira, pois não há, de maneira alguma, compreensão que compactue com uma afirmativa de que Coutinho e Serviço Social são distantes e, muito menos incompatíveis. Porém, a segunda afirmativa, embora faça uma indicação factual, é também um ponto muito generalista e, assim sendo, seria possível substituir o nome de Carlos Nelson Coutinho pelo nome de outro intelectual brasileiro marxista que, como ele, contribuiu na elucidação da tradição marxista e teoria marxiana no Brasil e, consequentemente, no Serviço Social, podendo estar em seu lugar Netto, Tonet, Konder, Lessa, entre outros importantes pesquisadores, intelectuais ${ }^{4}$.

Neste sentido que se empregou o esforço de levantar questões que tangenciem uma vinculação mais substantiva e orgânica entre Coutinho e Serviço Social. Foram, pois, formulados três porquês ${ }^{5}$ para sistematizar o que se pretende e trazer à baila algumas particularidades da figura intelectual de Carlos Nelson Coutinho. Então, por que Coutinho? Em primeiro lugar, porque Carlos Nelson Coutinho foi um dos mais importantes intelectuais para a renovação do marxismo no Brasil como tradutor e intérprete de Lukács e Gramsci no Brasil e que contribuiu à incidência deste último no Serviço Social ${ }^{6}$. Coutinho começou a fazer traduções desde muito jovem, em meados dos anos 1960, quando ainda morava na Bahia ${ }^{7}$. Sua primeira tradução foi aos 22 anos de idade, um livro de Gramsci, a Concepção dialética da história. Embora ele tenha demorado para reconhecer seu trabalho de tradutor, traduziu mais de setenta livros, um trabalho demasiadamente significativo. Nesse ofício, realizou traduções importantes para a entrada do pensamento marxista no Brasil. Segundo Netto (2012), é relevante observar que seu ofício de tradutor não significou um simples meio de vida, por quase vinte anos, mas constituiu sua própria reflexão, sendo que Lukács e Gramsci foram centrais à constituição de suas próprias obras. Assim se evidencia a originalidade e se consolida o pioneirismo de Coutinho na introdução das obras e do pensamento de Lukács e Gramsci no Brasil, contribuindo "decisivamente para a renovação do marxismo no país, quer pela sua difusão teórica, quer pela sua criativa utilização na análise da nossa história e da nossa cultura" (BRAZ, 2012, p. 11).

Coutinho (2012) explica que descobriu Lukács ainda quando estava na Faculdade de Direito na Bahia ${ }^{8}$. Um certo dia, na biblioteca da faculdade, estava com uma revista francesa que falava sobre o lançamento, na França, de Histoire et conscience de classe e, quando foi ao Rio de Janeiro, em 1961, adquiriu o livro, junto com seu primeiro exemplar de Gramsci. Conforme Simionatto (1995) a grande influência de Lukács na produção de Carlos Nelson Coutinho foi durante seu período de afastamento das atividades políticas diretas. Ainda assim, a autora mostra que o autor recorreu frequentemente ao pensamento de Gramsci em seus escritos sobre crítica literária9. Esta forte influência de Lukács pode ser considerada mais que isso, configurando-se, então, um período ou, como chamou Netto (2012), um “momento lukacsiano" de Carlos Nelson Coutinho. Esse período, como Coutinho (2012) mesmo denominou posteriormente, fanaticamente lukacsiano, ocorre entre os anos 1965 e 1976, representando a primeira fase da produção intelectual de Coutinho, a fase de "crítico da cultura" (SOUZA, 2013, p. 56). "Neste lapso temporal seu pensamento é profundamente vincado pela [...] impostação filosófica e cultural, situando-se no campo da crítica cultural, e, em grande medida por isso mesmo, nitidamente marcado pela referência a Lukács" (SOUZA, 2013, p. 59) ${ }^{10}$.

O momento fanaticamente lukacsiano é fundamental à compreensão do pensamento do autor ao longo de sua vida intelectual (SOUZA, 2013), pois embora seja esta uma fase ou um momento demarcadamente lukacsiano (1965-1975/1976), Coutinho nunca abandonou Lukács, isto é, a influência lukacsiana em sua produção intelectual continua presente, precisamente no que tange à interpretação do pensamento marxiano como ontologia do ser social, porém de maneira direta, remete-se a esta influência no período mencionado. Anota-se, pois, que não é em seu momento lukacsiano ou em sua produção intelectual de viés lukacsiano que Carlos Nelson Coutinho vai influenciar o Serviço Social brasileiro; da mesma forma, ao revés, não é por sua produção com base em Lukács que o filósofo brasileiro foi buscado como referência teórica pelo Serviço Social questão consensual entre os sujeitos entrevistados.

Para Netto (2012), a partir de 1969, por conta das implicações ainda do AI5, aquele culturalismo presente na produção de Coutinho desliza cada vez mais para a questão da política, o que evidencia outro momento do intelectual. Souza (2013) denominou como a segunda fase, a de intelectual orgânico e teórico da política, de meados dos anos 1970 até o fim da vida do intelectual ${ }^{11}$. Tal deslizar de que Netto fala ou a "virada do interesse central da filosofia e da crítica da cultura para a teoria política" de Coutinho, de que fala Souza (2013), "guardam relações mais profundas [...] com fenômenos sociais e políticos abrangentes com os quais Carlos Nelson se encontrava bastante envolvido no período em que se dá esta passagem a sua "fase madura" (SOUZA, 2013, p. 60). Cabe resgatar deste período, a discussão que permeou o pensamento de Coutinho e que refratou no Serviço Social brasileiro, pois o conteúdo da produção intelectual de Coutinho que vai, direta e indiretamente, rebater no Serviço Social brasileiro, aloca-se, justamente, na demarcada segunda fase, a de 
teórico da política, à luz do pensamento gramsciano. É neste período que o Serviço Social se aproxima mais substantivamente do pensamento gramsciano, buscado inicialmente por seu marxismo aberto.

Em segundo, porque Coutinho passou aproximadamente metade de sua vida intelectual vinculado à Escola de Serviço Social da Universidade Federal do Rio de Janeiro, mesmo não sendo assistente social, anotando que em 2016 ele completaria 30 anos com o Serviço Social ${ }^{12}$.

Assim, partir de sua entrada na ESS-UFRJ, as disciplinas por ele ministradas no curso de graduação e pós-graduação em Serviço Social e em outras áreas terão a obra e o pensamento gramsciano como eixo central (SIMIONATTO, 1995). Ainda, Coutinho realizou 13 orientações de mestrado e 14 orientações de doutorado, além das dezenas de bancas das quais participou.

Não é por acaso a relação de Coutinho com o Serviço Social brasileiro, até "a vida acadêmica de Carlos Nelson não pode ser dissociada do Serviço Social" (NETTO, 2015). Logo, o referido diálogo ou relação entre o intelectual e a profissão devem ser entendidos como uma contribuição dialética, mútua, recíproca. É evidente que, antes de mais nada, o Serviço Social deve muito mais a Coutinho, devido à sua trajetória e também ao legado que deixou; por outro lado, foi também o terreno escolhido por ele para trilhar quase toda a segunda metade de sua vida intelectual.

Sua entrada na ESS-UFRJ também não se configura como um acaso, como pode ser aferido na bibliografia estudada, bem como na fala dos sujeitos da pesquisa. Paiva (2016) explica que havia uma preocupação de qualificar professores do Programa de Pós-Graduação em Serviço Social da UFRJ - que, à época, ofertava apenas nível de mestrado - e, somado ao processo de redemocratização e abertura das universidades no país, muitos professores saíram para fazer o doutorado e alguns novos foram admitidos, entre os quais estava Coutinho.

Ramos (2013), tratando sobre o referido processo de renovação da ESS-UFRJ e da contribuição de Coutinho, entre outros importantes intelectuais, destaca a participação ativa deste junto ao Serviço Social, entre outros fatores de contribuição: a) sua intervenção enquanto professor de disciplinas da graduação, mestrado e doutorado; b) o grande número de dissertações e teses que orientou, todas assentadas na tradição marxista; c) sua rica produção científica; d) sua grande participação nas atividades acadêmicas e debates em geral: Coutinho se destaca em sua intervenção enquanto professor da universidade e sobretudo enquanto intelectual, que transcende a sua contribuição para a ESS-UFRJ, atingindo o Serviço Social brasileiro e latino americano, de maneira marcante - uma via de contribuição foi a visibilidade empregada ao ensino e à pesquisa; outra, a construção do debate em torno do pluralismo no interior da UFRJ, mas que se disseminou no Serviço Social brasileiro como um todo.

Em terceiro lugar, porque ele discute em suas produções muitas das categorias e conceitos presentes nos princípios fundamentais do Código de Ética Profissional de 1993. É importante fazer uma ressalva: este porque não implica que haja direta ou mecanicamente uma influência posta na concepção destes princípios sobre o que será tratado em seus meandros, mais adiante, uma vez que envolve diretamente à problemática da pesquisa em xeque.

Outra questão para situar este porque é que, as categorias e conceitos, no âmbito da tradição marxista, estudados, analisados e, algumas vezes, revisados por Coutinho em sua extensa obra correspondem ao antes e depois de seu entrecruzamento com o Serviço Social, porém, como visto e como se verá mais detalhadamente adiante, é a segunda fase do intelectual que se relaciona mais diretamente com o Serviço Social. Não há, portanto, uma categoria de Coutinho exclusivamente dimensionada para a profissão, mas os conceitos e categorias analisados que têm relação com a área profissional são buscados em sua produção, ou seja: Coutinho é um dos intérpretes marxistas buscados pelo Serviço Social para auxiliar na compreensão da realidade social.

Pensando, pois, nas categorias presentes nos princípios éticos e que traduzem e representam valores universais para a categoria profissional de Assistentes Sociais, os conceitos de democracia, pluralismo, éticopolítico, devem-se muito à discussão trazida por Coutinho. No interim destes porquês, afirma-se pelo alto e sem medo de errar que Carlos Nelson Coutinho teve enorme contributo com sua produção intelectual, mas, no que tange à análise objetiva de sua influência, como intérprete marxista e teórico da política, na elaboração dos princípios éticos fundamentais ou em torno da compreensão conceitual das categorias presentes ali, é parte constitutiva e responsável por elucidar brevemente a questão, no item a seguir.

\section{Resultados e discussão: formas de influência de Coutinho para elaboração dos princípios éticos fundamentais do Código de 1993}

No momento em que é possível (re)conhecer a relação entre Carlos Nelson Coutinho com o Serviço Social brasileiro, no interim de uma intersecção que se logra antes e durante a entrada do intelectual como docente na Escola de Serviço Social da UFRJ, é possível, também, compreender como se processa esta 
relação, tanto sobre reconhecer a fase do intelectual que influencia expressivamente o Serviço Social, quanto ao revés, quando em qual momento da profissão seus sujeitos profissionais buscam a bibliografia e a figura de Coutinho para intervenções. Porém, a compreensão sobre a influência de Coutinho quando da elaboração dos princípios éticos fundamentais do Código de Ética de 1993 só é possível a partir daquilo que os sujeitos membros da Comissão Técnica de reformulação trazem em sua interpretação e memória histórica do processo, enquanto intelectuais do Serviço Social brasileiro, os quais se constituem também referências de conhecimento acumulado a partir de suas trajetórias pessoais, profissionais e políticas.

Neste caminho, com efeito, a chamada intersecção entre Coutinho e o Serviço Social é o panorama para compreender sua influência na formulação dos princípios do Código. Desta forma, no desenrolar da pesquisa foram desnudando-se formas de influência do intelectual marxista convicto e confesso, no sentido de que não houve uma influência única, linear e homogênea, configurando, pois, uma influência que pode ser caracterizada em dois níveis.

\section{Influência indireta}

Carlos Nelson Coutinho chega para o Serviço Social brasileiro antes mesmo de sua entrada na Escola de Serviço Social da UFRJ, de forma que o diálogo entre ambos ocorre em um momento em que está se gestando, no interior da profissão, um processo de questionamento e afastamento progressivo com suas bases conservadoras, o que Netto (2012) denominou de intenção de ruptura (1975-1985), período mesmo em que Coutinho já se encontrava intelectualmente em sua fase de teórico da política (1975-2012). É quando, no início do declínio do regime ditatorial, a profissão começa a buscar o pensamento gramsciano e Coutinho está retornando do exílio. O lastro temporal, pois, que marca o início de um diálogo, donde os meandros de sua influência para a profissão e, mais especificamente, para a formulação dos princípios éticos fundamentais do Código de Ética, é o final da década de 1970. A partir daí configura-se o primeiro nível da influência de Coutinho, que foi chamado de influência indireta, já que suas obras bem como seu trabalho intelectual como um todo, chegam ao Serviço Social de maneira intencional e indireta, havendo neste nível de influência dois momentos distintos.

O primeiro momento é demarcado por uma influência que chega do final dos anos 1970 estendendo-se até 1986, antes de sua entrada na ESS-UFRJ, que se desenvolve por meio do trabalho do intelectual de tradutor dos textos de Gramsci, assim como por sua militância no PCB e, ainda, por seu conhecido ensaio que discute o conceito de democracia como o caminho para o socialismo, que chegou a vários espaços (acadêmicos, profissionais, políticos, partidários) e não apenas à profissão em questão.

Na entrada dos anos 1980, como se sabe, Coutinho já era um nome de influência nacional, não apenas pelo conjunto de sua obra, mas certamente pelo ensaio produzido logo após o retorno do exílio, em 1979, "A democracia como valor universal", que teve um papel decisivo para o pensamento político da esquerda e, consequentemente, esse debate vai rebater no Serviço Social, ainda que de forma indireta e não imediata: "nos anos 1980, onde ele não ainda atua intensivamente por dentro do Serviço Social e a influência que chega é pelo impacto, sobretudo, das ideias do pluralismo e da democracia na cultura política brasileira, onde Carlos Nelson se constitui como uma referência do pensamento de esquerda, então, por aí sem ter vinculação imediata ele rebate no Serviço Social" (NETTO, 2015).

Este debate que Coutinho faz em seu ensaio é muito vincado por sua experiência com o eurocomunismo do Partido Comunista Italiano, em um momento de renovação dos partidos comunistas no mundo inteiro, como explica Paiva (2016). Assim, sua discussão rebate em vários segmentos da sociedade brasileira, com muitas concordâncias e (mais ainda) discordâncias de sua tese sobre a democracia. E esta discussão rebate para o Serviço Social pensar a categoria de democracia? Evidentemente sim, no entanto não há uma transposição mecânica ou automática de sua compreensão sobre democracia - que está plasmada no interior do espaço de disputas que são os partidos - para o âmbito do Serviço Social, tampouco diretamente para a formulação do princípio, mais a diante na história.

De acordo com Paiva (2016), de fato houve este debate da "democracia como valor universal" no interior da categoria, porém não foi incorporada, nem à época de publicação do ensaio nem à época de elaboração dos princípios éticos fundamentais, considerando que a própria produção de Coutinho não pode ser mimetizada ou transposta de forma direta à discussão no espaço de uma profissão, já que pertence a outra discussão e contexto histórico.

Embora tenha se logrado a eleição de valores universais que pudessem traduzir o compromisso com a classe trabalhadora e com o ser humano em sua genericidade, essa universalidade no âmbito da dimensão de democracia "é distinta daquela que o Carlos Nelson formulou no diálogo dele dentro do Partido Comunista Brasileiro" (PAIVA, 2016). Entretanto, quando da elaboração dos princípios, foi elencado um conjunto de 
valores que portam universalidade e, no que tange à concepção da democracia, só foi possível porque havia um debate com Coutinho e, ainda que não fosse uma correspondência direta de suas formulações, elas foram essenciais para trazer à baila o debate e a reflexão à-hora-do-dia. Assim, a qualificação da democracia como eliminação de todas as formas de opressão, de exploração, mais especificamente a democracia entendida como socialização da política e da riqueza socialmente produzida, se deve (também, mas não só) ao debate plural com o intelectual, como concluiu a entrevistada: "se fizemos essa qualificação da democracia é porque tínhamos um debate com Carlos Nelson, por mais que não tivéssemos sido um espelho das formulações dele, sem suas provocações e reflexões [...] não teríamos ousado e sido críticos da maneira como fomos [...] ele foi absolutamente fundamental" (PAIVA, 2016).

A denominada intersecção ou relação de contato direto entre Carlos Nelson Coutinho e o Serviço Social ocorre, é sabido, a partir de 1986, quando o intelectual passa a fazer parte do corpo docente da ESS-UFRJ. Neste sentido, o segundo momento de sua influência indireta se situa no período entre 1986 e 1991, que abarca os primeiros anos de Coutinho como docente da referida escola, quando começa a ministrar aulas na Graduação de Serviço Social e no Mestrado, vinculado ao Departamento de Políticas Sociais desta mesma escola, iniciando, mais tarde, também ali, suas primeiras orientações de dissertações de dentro do Serviço Social.

Urge explicar o porquê deste recorte temporal, bem como o porquê desta influência, mesmo de dentro da ESS-UFRJ se configurar como uma influência indireta de Coutinho para o Serviço Social e, consequentemente, para a construção dos princípios éticos fundamentais que perpassam todo o projeto ético-político profissional. Em primeiro lugar, o recorte temporal sinalizado relaciona-se diretamente ao objeto da pesquisa da dissertação, uma vez que o processo de reformulação do Código de Ética de 1986, a elaboração dos princípios éticos presentes e a culminação na aprovação do Código de Ética se encerram quando da aprovação da Resolução CFESS n. 273/1993, em 13 de março de 1993, sendo que sua discussão, reflexão e elaboração é fomentada entre os anos 1991 e 1992. Em segundo lugar, Coutinho, mesmo fazendo parte do corpo docente do Serviço Social, nunca produziu conhecimento sobre a profissão diretamente, porém isso não é auto evidente ao fato de sua influência ser indireta neste momento, já que sua marcada presença junto à profissão, mesmo não sendo assistente social, trouxe contribuições substantivas e influenciou diretamente o Serviço Social, como se verá. Mas, porque no período demarcado Coutinho ainda estava se aproximando do universo do Serviço Social e, até ali, não havia realizado nem mesmo suas primeiras orientações de mestrado. Assim como, porque a partir do final do ano 1990, início de 1991 sua influência começa a se configurar em outro nível, como será visto.

Logo, Coutinho influencia diretamente seus alunos, no entanto esta influência é direta com relação a determinados sujeitos e não em relação à elaboração dos princípios do Código. Em outras palavras: sua influência se caracteriza como indireta, neste segundo momento porque ela toca diretamente suas alunas e seus alunos, alguns que foram protagonistas no processo de reformulação e de elaboração dos princípios, como é o caso de Mione A. Sales, sua aluna (e, mais tarde, orientanda) e Beatriz Paiva, sua aluna na graduação e no mestrado de Serviço Social - recordando que ambas foram membro da Comissão Técnica de Reformulação do Código.

De modo geral, existe um consenso no que se refere à contribuição e importância da influência de Coutinho para discentes, docentes e profissionais do Serviço Social, desde alguns registros em periódicos recentes, como nas falas dos sujeitos da pesquisa. Para Barroco (2016), Coutinho influenciou toda uma geração do Serviço Social com sua presença marcante, auxiliando na e ampliando a compreensão em torno do "legado de Marx, de Lukács e especialmente de Gramsci, o que necessariamente rebateu na maturidade da tendência marxista do serviço social, no projeto ético-político e no Código de Ética". Neste caminho, Paiva (2016) explica que ela e Mione A. Sales foram alunas de Carlos Nelson Coutinho e liam toda a bibliografia que ele indicava, já em sua fase de teórico da política ou se se preferir em sua fase gramsciana - mesmo sem nunca ter deixado de ser lukacsiano. Coutinho foi um interlocutor muito presente, na leitura e compreensão daquilo que era o debate da ética no Serviço Social, ministrava aulas, participava de bancas, ia aos eventos e, mesmo não sendo e não estudando especificamente a área profissional do Serviço Social, tampouco tenha construído algum documento diretamente relacionado à reformulação, registrou, certamente, uma participação fundamental no debate na graduação e na pós-graduação.

Paiva (2016) ressalta a importância fundamental que Coutinho teve no que se refere à categoria de práxis revolucionária. Isso porque, as aulas e a leitura das produções de Carlos Nelson Coutinho traziam elementos e subsídios muito concretos para a discussão da práxis revolucionária; juntamente com Konder, que também contribuiu em alguns importantes momentos, na apropriação do que é a ética no marxismo. Nas palavras da referida entrevistada, "foi nas disciplinas deles que tomamos conhecimento desses autores [Agnes Heller, Lukács], então, a participação dele foi indireta, mas foi decisiva. Indireta porque não estava na comissão, ele não discutiu na comissão nem a profissão, mas no campo teórico e ético-filosófico, sim" (PAIVA, 2016). No que se refere ao debate sobre a ética, Paiva (2016) ressalta, ainda, que Coutinho, desde sua chegada à ESS-UFRJ, nos Congressos (CBAS), nos grandes Seminários Nacionais da ABEPSS, do 
CFESS, das entidades da categoria, era sempre um dos principais palestrantes, trabalhando grandes temas e, embora não tenha sido um interlocutor direto para a discussão da ética, foi um enorme interlocutor para a categoria poder pensar a amplitude da constituição dos valores universais dentro do campo marxista. Por isso, a entrevistada considera que o acúmulo produzido para o debate sobre o Código de 1993 se deve, no espaço da filosofia, primordialmente, a Coutinho.

Em consonância, Vinagre (2016) afirma que a contribuição de um intelectual como Coutinho não é somente para o Serviço Social, mas para toda a esquerda brasileira. Certamente, não é possível (e não é este o propósito) expressar e se vincular, quando da formulação de Código de Ética profissional ao pensamento de um único autor, mas, como explica a entrevistada, toda a discussão daquele momento tinha como ponto de partida uma crítica ao marxismo enviesado e, por consequência, tendo a ontologia como ponto central, donde a plena emancipação dos indivíduos sociais é que traçava a linha do horizonte, "entra, não só, o pensamento lukacsiano, como gramsciano e como o pensamento da formulação marxiana, propriamente dita, como ferramentas analíticas e que ancoram aquela elaboração" (VINAGRE, 2016). Daí a compreensão de que, embora a contribuição e influência de Coutinho não tenha sido direta nem exclusiva neste espaço, ela foi fundamental.

Com efeito, o que poderia ser aferido, caso houvesse possibilidade de mensurar as falas dos sujeitos da pesquisa, é que a contribuição e influência de Coutinho está longe de ser pontual ou específica, assegurada numa influência num ou noutro princípio, configurando sutilmente aquilo que a própria dialética no materialismo histórico conduz: a ausência de linearidade. A contribuição e influência de Coutinho para a elaboração dos princípios é coerente mesmo com sua trajetória intelectual e posicionamento político, assim como descreveu Barroco (2016) em completude e síntese. Carlos Nelson era um intelectual no sentido dado por Gramsci do intelectual orgânico; a articulação entre sua profunda capacidade teórica, no âmbito do pensamento de Marx. Lukács e Gramsci, e seu engajamento político marcou sua trajetória.

Desta forma, a perspectiva do marxista convicto e confesso, de caráter ontológico parece não permitir uma contribuição ou influência onde defina conceitos e categorias específicas, assim como observou Barroco: "Sua apreensão destas categorias é pautada na perspectiva de totalidade e no entendimento de que tais categorias são modos de ser objetivos e historicamente construídos pelo ser social; [...] definir tais categorias demandaria reproduzir a produção teórica do autor, [e] não se trata de uma definição, mas de entender cada uma dessas manifestações no interior de uma fundamentação ampla" (BARROCO, 2016).

Da mesma forma como se articulam os princípios éticos fundamentais, é expressamente impossível discutir cada um deles isoladamente, isso porque, no âmbito da perspectiva teórico-metodológica em que foram formulados, não há como falar em liberdade sem pensar em democracia, sem remeter ao pluralismo e, por sua vez, não é possível pensar em emancipação sem pensar em igualdade, dentro, pois, de um projeto societário distante de qualquer forma de exploração, distinto do vigente - horizonte que a profissão se propõe e objetiva somar forças.

No entanto, é preciso registrar aquilo que veio à baila no processo da pesquisa e que ressalta uma categoria em específico em que a contribuição conceitual feita por Coutinho foi fundamental. Para não se cair em contradição diante da afirmação supra, é preciso anotar que mesmo que esta seja uma categoria que tenha sobressaído enquanto contribuição factual e direta de Coutinho, ela não está alheia do conjunto de sua obra, ao revés: ela é inerente às formulações no campo da tradição marxista que o intelectual desenvolveu ao longo de sua vida, assim como ela não pode existir isoladamente sem a referência e articulação a outros valores e categorias.

Com efeito, a contribuição que surge em 1991 e que será chamada de grande influência é que abre caminho para sua influência direta, não só ao que se refere aos princípios fundamentais, mas à profissão de maneira geral, pois: "no momento em que o Código está sendo reformulado, a influência do Carlos Nelson vinha muito menos pelos seus textos, do que o impacto na cultura política e dos seus alunos" (NETTO, 2016).

\section{Influência direta}

O segundo nível de influência de Coutinho tangencia uma influência direta do intelectual para o Serviço Social brasileiro que se inicia, primeiramente, no espaço da ESS-UFRJ e, por conseguinte, espraia-se pelos diversos espaços acadêmicos e profissionais no país, quando de sua participação em eventos, palestras e debates da categoria, bem como por meio da ampliação de suas orientações a alunas e alunos do mestrado e doutorado. Desta forma, embora Coutinho não fosse assistente social e nem produzisse conhecimento sobre a profissão em si, ele refletiu, debateu e produziu, quase sempre ou sempre, conteúdos base para os fundamentos históricos e teórico-metodológicos do Serviço Social, sendo certamente um dos mais importantes intérpretes do marxismo para a profissão no Brasil - além de toda sua contribuição à renovação do marxismo no país, como visto brevemente linhas atrás. 
A abertura da chamada influência direta de Coutinho para o Serviço Social é, justamente, sua grande influência e contribuição em torno de um conceito no âmbito dos princípios fundamentais do Código de Ética de 1993, qual seja, o pluralismo. Foi no ano de 1990 - e por isso aqui se inicia a demarcação temporal da influência direta, pois se trata de um marco histórico de contribuição de Coutinho para a categoria profissional, da forma como todos sujeitos da pesquisa destacaram - no I Seminário Nacional de Ensino em Serviço Social (graduação e pós-graduação), com o tema Pluralismo e Formação Profissional, realizado na Pontifícia Universidade Católica de Minas Gerais - PUC-MG, em Belo Horizonte, que Coutinho ministrou uma palestra sobre o pluralismo.

Mesmo que sua influência se evidencie de maneira direta, a partir deste marco em 1990, não é possível não considerar sua influência indireta, como explicitado anteriormente, da forma como os sujeitos da pesquisa também reforçaram. Por outro lado, em consonância com Netto (2016), considera-se que esta é, de fato, a primeira manifestação de influência direta de Coutinho para o Serviço Social, tocando, inclusive, um dos princípios do Código de Ética e, por essas razões, foi chamada aqui de grande influência, que se expande quando da publicação da referida intervenção em forma de ensaio/artigo. Nesta exposição, Coutinho (1991) define duas dimensões básicas para abordar a discussão sobre o pluralismo: o pluralismo enquanto fenômeno social e político; e, o pluralismo na construção do conhecimento ou as implicações do pluralismo na questão da epistemologia.

Nesse sentido, Vinagre (2016), quando fala sobre a contribuição de Coutinho para o Serviço Social e para o pensamento social crítico brasileiro, ressalta sua importância no contexto de reformulação do Código, a partir da discussão da teoria política de Gramsci, e primordialmente no seu debate sobre o pluralismo. Ela explica que foi neste debate sobre o pluralismo que, pela primeira vez, o Serviço Social conheceu de fato o que significava pluralismo, haja vista que até então se fazia, quase sempre, o uso equivocado do termo, empregando-lhe significado ou concepção de ecletismo.

De acordo com o que a pesquisa pode trazer à luz, é neste interim - de uma discussão e compreensão de pluralismo - considerando suas duas dimensões, haja vista que o Serviço Social tanto possui uma direção sócio-política enquanto profissão, quanto produz conhecimento em torno da realidade de sua intervenção, bem como sobre sua práxis profissional em si, onde não há lugar para ecletismo, - articulado à concepção de hegemonia e à compreensão da constituição dos valores como objetivos e como resultado de uma construção coletiva - que se evidencia a grande contribuição de Coutinho tanto para o estabelecimento da concepção em torno o pluralismo, como para o reconhecimento, de modo geral, da ampliação da concepção em torno da defesa de determinados valores ético-universais, pensando naqueles valores presentes nos princípios éticos fundamentais que norteiam e perpassam a práxis profissional.

Como se sabe, historicamente há uma grande lacuna

... Coutinho contribuiu mesmo que de forma indireta à compreensão da ética no âmbito da ontologia do ser social e da política como uma categoria que extrapola as relações de poder, contribuindo à reflexão da compreensão de ambas como categorias que essencialmente se articulam. no que tange à conceituação e, portanto, uma confusão ainda maior à compreensão de pluralismo para a categoria profissional do Serviço Social. E, pode-se dizer que, esta confusão abrangia as duas dimensões básicas trazidas por Coutinho (1991). É preciso dizer que esta é ainda uma lacuna para boa parte de profissionais, pois nos textos ou nas falas de muitos, a única referência ao pluralismo vem no âmbito da epistemologia, quando se discute a produção de conhecimento dentro de uma determinada perspectiva teóricometodológica, onde a concepção fica restrita à definição, segundo a qual pluralismo é diferente de ecletismo. Neste sentido, o pluralismo era visto pela categoria como uma mistificação e foi Coutinho, numa elaboração a partir do e com o conceito gramsciano de hegemonia, que auxiliou no processo de compreensão da mesma, assim como Paiva afirma em sua fala: "Coutinho, a partir do conceito de hegemonia, ajudou a entender como é que se constrói o debate político dentro de um universo heterogêneo garantindo a hegemonia de determinada perspectiva teórica sem que precisássemos destruir a outra" (PAIVA, 2016). A compreensão do pluralismo articulado com hegemonia engendrou uma aproximação e entendimento também do conceito de hegemonia, o que, certamente, se configurou também como uma contribuição de Coutinho para o Serviço Social no contexto de reformulação do Código de Ética, que culmina no Código de 1993. A própria compreensão da hegemonia não como uma maioria, mas como uma força de debate que se chega a um consenso coletivo entre os diferentes, isto é, de uma unidade na diversidade, advém fundamentalmente desta discussão de Coutinho, no âmbito da tradição marxista. Paiva (2016) chama à 
atenção, ainda, ao fato de que, não fosse esta concepção de pluralismo com hegemonia, talvez, a proposta e o processo da reformulação do Código pudesse ter cessado antes de sua conclusão, residindo aí, ao que pode ser analisado, a grande influência de Coutinho para a categoria profissional. Para além disso, a contribuição ou influência de Coutinho, não só está presente no espaço delimitado na pesquisa que engendra esta dissertação, isto é, não está apenas vívido no âmbito de uma influência para a elaboração dos princípios éticos fundamentais, mas, de modo geral, ela é transcendente e passa a ser efetivamente uma influência direta no período posterior a 1990 - a partir de sua grande influência com o pluralismo, bem como com sua intervenção na PUCSP sobre Gramsci e as ciências sociais - especialmente a partir de 1994, como se evidenciou durante a travessia da pesquisa de campo e assim como é reconhecido nacionalmente dentro e fora do Serviço Social, haja vista que sua contribuição e influência não cessa aí, ao revés: ela se evidencia ainda mais fortemente, de maneira mais direta e mais presente, tangenciando o que se compreendeu como um legado de Carlos Nelson Coutinho no interior de sua fase de teórico da política e a partir de sua grande influência. E por que essa referência pós 1991 e, especialmente, pós 1994? Primeiramente, 1991 é o marco da grande influência, assim como é nos anos posteriores que Coutinho inicia suas orientações a nível de mestrado, no espaço do Serviço Social - sem esquecer de sua presença ativa na docência e também nas atividades da graduação, conforme reforçou Teixeira (2016), considerando que Coutinho nunca deixou de manter-se próximo de alunas e alunos desta. Mas veja, desde sua entrada na UFRJ em 1986, até 1993, Carlos Nelson Coutinho orientou somente duas alunas do programa de mestrado.

Portanto, é a partir de 1994 que a influência de Coutinho muda de qualidade, como observou Netto (2016), podendo configurar, então, o início da construção de um legado deste intelectual ao Serviço Social brasileiro, extrapolando o espaço de delimitação desta pesquisa e, consequentemente deste artigo e, por isso mesmo, carece continuar sendo estudado.

\section{Considerações finais}

A contribuição e a influência de Coutinho estão longe de ser pontual ou específica. Ao contrário, foi uma contribuição fundamental e extremamente qualitativa, que rebateu direta e indiretamente no Serviço Social e ainda rebate. Porém, há que se (re)dizer e afirmar que tanto para a concepção em torno da ética e, ainda mais, em torno do conceito de política, o marxista convicto e confesso foi fundamental, porque partindo de uma perspectiva teórico-metodológica histórico-crítica, Coutinho contribuiu mesmo que de forma indireta à compreensão da ética no âmbito da ontologia do ser social e da política como uma categoria que extrapola as relações de poder, contribuindo à reflexão da compreensão de ambas como categorias que essencialmente se articulam. Naquele período de reformulação, tanto sua discussão sobre democracia que rebateu não somente no Serviço Social, mas em vários outros segmentos sociais, quanto seu debate específico para o Serviço Social, e que também o extrapola, sobre pluralismo, marcam profundamente a discussão e reflexão sobre categorias que viriam a ser (e o são) dois dos princípios éticos fundamentais do Código de Ética Profissional do Serviço Social brasileiro. Tais princípios que são valores universais e não podem ser compreendidos de maneira isolada, porque são articulados e se complementam dando norte ao exercício profissional, bem como, no âmbito da totalidade e materialidade do projeto profissional, orientam à construção de uma nova ordem societária ${ }^{13}$.

\section{Referências}

BARROCO, M. L. S. O processo de reformulação do Código de Ética de 1986 e a influência de Carlos Nelson Coutinho para a elaboração dos princípios éticos fundamentais presentes no Código de Ética Profissional do(a) Assistente Social de 1993 no Brasil. São Paulo, jun. 2016. [Entrevista - arquivo digital]

BONETTI, D. A. et al (Orgs.). Serviço Social e Ética: convite a uma nova práxis. 13. ed. São Paulo: Cortez, 2012.

BRAZ, M. (Org.). Carlos Nelson Coutinho e a renovação do marxismo no Brasil. São Paulo: Expressão Popular, 2012.

CAZELA, M. C. Princípios éticos fundamentais do Serviço Social brasileiro: um estudo sobre a influência de Carlos Nelson Coutinho. 2016. 150 f. Dissertação (Mestrado em Serviço Social) - Universidade Estadual do Oeste do Paraná, Toledo, 2016.

COUTINHO, C. N. Conversa com um "marxista convicto e confesso". In: BRAZ, M. (Org.). Carlos Nelson Coutinho e a renovação do Marxismo no Brasil. São Paulo: Expressão Popular, 2012. p. 397-420.

. Pluralismo: dimensões teóricas e políticas. Cadernos ABESS, n. 4, p. 05-17, 1991.

GIL, A. C. Metodologia de Pesquisa em Serviço Social. Caderno Técnico 23. Brasília. CNI/SESI, 1996.

NETTO, J. P. Breve nota sobre um marxista convicto e confesso. In: BRAZ, M. (Org.). Carlos Nelson Coutinho e a renovação do marxismo no Brasil. São Paulo: Expressão Popular, 2012. p. 51-83. 
. Homenagem póstuma o Professor Dr. Carlos Nelson Coutinho. $8^{\circ}$ Seminário de Serviço Social da Editora Cortez. Pontifícia Universidade Católica de São Paulo - PUC-SP. 11 de maio de 2015 [Vídeo publicado em 13 de agosto de 2015]. Disponível em: <https:/ /www.youtube.com/watch?v=aV3Jjqkp818>. Acesso em: 17 de ago. 2015.

. O processo de reformulação do Código de Ética de 1986 e a influência de Carlos Nelson Coutinho para a elaboração dos princípios éticos fundamentais presentes no Código de Ética Profissional do(a) Assistente Social de 1993 no Brasil. Rio de Janeiro, 28 abr. 2016. [Entrevista - arquivo digital]

PAIVA, B. A. O processo de reformulação do Código de Ética de 1986 e a influência de Carlos Nelson Coutinho para a elaboração dos princípios éticos fundamentais presentes no Código de Ética Profissional do(a) Assistente Social de 1993 no Brasil. Florianópolis, mar. 2016. [Entrevista - arquivo digital]

RAMOS, M. H. R. Memórias do processo de renovação da Escola de Serviço Social da URRJ e da contribuição de Carlos Nelson Coutinho. Revista Praia Vermelha, Rio de Janeiro, v. 22, n. 2, p.77-85, jan./jun. 2013.

SIMIONATTO, I. Gramsci: sua teoria, incidência no Brasil, influência no Serviço Social. São Paulo: Cortez; Florianópolis: Editora da UFSC, 1995.

SOUZA, V. N. Um marxista na batalha das ideias: Carlos Nelson Coutinho e os caminhos da revolução brasileira. Praia Vermelha, Rio de Janeiro, v. 22, n. 2, p.49-75, jan./jun. 2013.

TEIXEIRA, A. Uma conversa sobre os traços de influência de Carlos Nelson Coutinho para o Serviço Social brasileiro. Rio de Janeiro, abr. 2016. [Entrevista - arquivo digital]

VINAGRE, M. O processo de reformulação do Código de Ética de 1986 e a influência de Carlos Nelson Coutinho para a elaboração dos princípios éticos fundamentais presentes no Código de Ética Profissional do(a) Assistente Social de 1993 no Brasil. Rio de Janeiro, abr. 2016. [Entrevista - arquivo digital]

\section{Notas}

1 Todas as entrevistas foram feitas no ano de 2016, por isso a referência (sujeito, ano) no corpo do texto.

2 Foi possível conhecer e conversar com Andréa Teixeira na ocasião da banca de defesa da tese de Victor Neves de Souza, Democracia e revolução: um estudo do pensamento político de Carlos Nelson Coutinho, qualificada pelos membros da banca avaliadora como uma biografia intelectual do marxista convicto e confesso.

3 Neste processo, registro que a condição como bolsista pesquisadora da CAPES foi essencial para a realização da pesquisa de campo, sobretudo a condição de poder ter dedicação integral e exclusiva; assim como a possibilidade de acessar recursos do Programa de Mestrado da UNIOESTE, campus Toledo/PR, para a pesquisa de campo.

4 É preciso investigar os meandros de contribuição de intelectuais que dialogaram com o Serviço Social brasileiro, assistentes sociais ou não, e que influenciaram a profissão historicamente. É preciso, principalmente em tempos de reação conservadora como a que se passa na sociedade e, consequentemente, na profissão, compreender mais a fundo e dar visibilidade à contribuição destes intelectuais para a profissão.

5 Não há nestes porquês uma disposição cronológica ou progressiva, ao contrário, há uma articulação entre eles, pois são expressão da realidade que nada tem de linear, mas aqui, para fins de exposição, foram assim enumerados.

6 Sobre a incidência de Gramsci no Brasil e no Serviço Social, ir ao conhecido e importante livro de Ivete Simionatto (1995), que constitui de parte de sua tese de doutoramento em Serviço Social na PUC-SP.

7 Carlos Nelson Coutinho, filho de Nathan Coutinho do Rosário e Elza de Souza Coutinho, nasceu em Itabuna (BA) em 28 de junho de 1943. Quando criança sua família se mudou para Salvador, onde residiu até 1965, quando concluiu o curso de Bacharel em Filosofia pela UFBA, único título formal de formação acadêmica de Coutinho.

8 Coutinho ingressou no curso de Direito da UFBA em 1961 e, em 1962, transferiu para o curso de Filosofia.

9 Simionatto (1995, p. 124) identifica que Coutinho utiliza categorias como "nacional-popular", o que fica muito evidente no ensaio que ele elabora em 1972, "O significado de Lima Barreto em nossa literatura".

10 "Mas a referência apenas a Lukács, seéfundamental para compreender o intelectual neste momento de sua produção, éinsuficiente: neste entretempo lêmarxistas diversos, muitos dos quais considerados "heterodoxos pela linha oficial [...], devolvendo uma característica marcante de seu pensamento ao longo de toda a vida - qual seja, um marxismo aberto ao diferente e ao contraditório, comprometido com a pluralidade de posições e extremamente bem informado sobre as diferentes interpretações relacionadas aos problemas com os quais enfrentava“ (SOUZA, 2013, p. 59, grifos do autor).

11 No dia 20 de setembro de 2012, falecera aos 69 anos, no Rio de Janeiro, Carlos Nelson Coutinho, marxista convicto e confesso, vítima de um câncer pulmonar.

12 O ano de 2016 demarca comemorações, na resistência e na luta: 80 anos de Serviço Social; 60 anos da fundação da antiga Associação Brasileira de Ensino em Serviço Social (ABESS), atual Associação Brasileira de Ensino e Pesquisa em Serviço Social (ABEPSS); 20 anos de Diretrizes Curriculares; e, também, 30 anos com Coutinho.

13 Uma discussão mais ampliada sobre o processo de reformulação do Código de Ética, bem como do processo de elaboração dos princípios fundamentais do Código vigente, encontra-se no texto completo da dissertação, em: CAZELA, M. C. Princípios éticos fundamentais do Serviço Social brasileiro: um estudo sobre a influência de Carlos Nelson Coutinho. 2016. 150f. Dissertação (Mestrado em Serviço Social) - Universidade Estadual do Oeste do Paraná, Toledo, 2016. 


\section{Mabile Caetano Cazela}

mabileccazela@hotmail.com

Assistente Social da Prefeitura de Foz do Iguaçu, Paraná

Mestre em Serviço Social pela Universidade Estadual do Oeste do Paraná (Unioeste), campus Toledo

\section{UNIOESTE}

Rua da Faculdade, 645 - Jardim La Salle

Toledo - Paraná - Brasil

CEP: 85.903-000 